\section{Aspergillus species isolated from mangrove forests in Borneo Island, Sarawak, Malaysia}

\section{Jaya Seelan Sathiya Seelan ${ }^{1}$, A.A.K. Faisal Ali $^{2}$ \& Sepiah Muid ${ }^{3}$}

${ }^{1}$ Institute for Tropical Biology and Conservation, Locked Bag 2073, Universiti Malaysia Sabah, 88999 Kota Kinabalu, Sabah, Malaysia ${ }^{2}$ Department of Biological Sciences, Texas Tech University, Lubbock, Texas 79409-3131, USA

${ }^{3}$ Department of Plant Science and Environmental Ecology, Faculty of Resource Science and Technology, 94300 Kota Samarahan, Universiti Malaysia Sarawak, Malaysia

Email: avinash80us@yahoo.com ${ }^{1}$

The occurrence of Aspergillus is worldwide but mainly in tropical and subtropical regions (Domsch et al. 1980; Christensen \& Tuthill 1985). Aspergillus spp. are isolated from soil, sea water, plant debris, compost and litter (Raper \& Fennell 1965). Aspergillus spp. are able to develop into many new strains through the process of heterokaryosis or parasexual reproduction and result high diversity in the environment (Raper \& Fennell, 1977; Papagianni 2004). This study aims to project the diversity of Aspergillus spp. on mangrove soil and leaf litters of four mangrove locations in Sarawak.

\section{Materials and Methods}

Sample collection and fungal isolation: Mangrove soil and 100-200 g of dried leaf litters were collected at random from four locations, i.e. Sematan, Lundu, Kampung Bako, Bako in the Borneo Island of Sarawak. Soil samples were pretreated following Warcup (1950). Five replicates were made for different soil samples and incubated at $28^{\circ} \mathrm{C}$ for seven days. Dried leaf litter samples were sliced into $1 \mathrm{~cm}$ pieces, directly plated onto Malt Extract Agar (MEA) and then incubated at $28^{\circ} \mathrm{C}$ for seven days.

Date of online publication 26 June 2009

ISSN 0974-7907 (online) | 0974-7893 (print)

Editor: V.B. Hosagoudar

\section{Manuscript details:}

Ms \# 02192

Received 30 April 2009

Final received 03 June 2009

Finally accepted 17 June 2009

Citation: Seelan, J.S.S., A.K.K.F. Ali \& S. Muid (2009). Aspergillus species isolated from mangrove forests in Borneo Island, Sarawak, Malaysia. Journal of Threatened Taxa 1(6): 344-346.

Copyright: (C) Jaya Seelan Sathiya Seelan, A.K.K. Faisal Ali \& Sepiah Muid 2009. Creative Commons Attribution 3.0 Unported License. JoTT allows unrestricted use of this article in any medium for non-profit purposes, reproduction and distribution by providing adequate credit to the authors and the source of publication.

Acknowledgements: Authors thank Universiti Malaysia Sarawak (UNIMAS) for permission and MOSTI for financial support. They are grateful to Prof. Maren Klich of the United States Agricultural Department (USDA) for confirmation of identification.

OPEN ACGESS | FREE DOWNLOAD

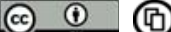

Identification: For identification, the fungi isolates were grown on five different media such as Czapek Yeast Extract Agar incubated at $25^{\circ} \mathrm{C}$ (CYA25), CYA37 (incubated at $37^{\circ} \mathrm{C}$ ), CY2OS (added with $20 \%$ sucrose incubated at $25^{\circ} \mathrm{C}$ ), Malt Extract Agar (MEA) and Czapek Dox solution agar $(\mathrm{CZ})$ (incubated at $25^{\circ} \mathrm{C}$ ). For each culture, five plates were used in triplicates. Each plate was inoculated at three points, equidistant from the center and incubated in the dark for seven days. The strains were identified using current universal keys of identification (Raper \& Fennell 1977; Pitt 1979; Domsch et al. 1980; Klich 2002). Notes of IMI description were also used for identification.

\section{Microscopic Observation}

A small tuft of mycelium and conidiophores were lifted from a fairly young portion of the colony, placed in a drop of alcohol on a glass slide and gently teased out. A drop of lactophenol blue or acid fuchsin was used to stain. The appearance of foot cell, conidiophores, presence of metulae (sterigmata) and conidia were observed. Digital photographs were taken by a Nikon camera attached to Leica Microscope.

\section{Result and Discussion}

Fungal Isolation: A total of 138 isolates belonging to five species of Aspergillus were isolated from the mangrove soil and leaf litter samples, collected from different sampling sites in four mangrove forests in Sarawak. Based on both macroscopic and microscopic observations, using an identification key, individual isolates were classified within the genus Aspergillus, belonging to three subgenera, four section and five species. The fungal isolates were identified as $A$. terreus Thom, $A$. flavipes Bainier and Sartory, A. carneus Blochwitz, A. fumigatus Fresenius and $A$. clavatus Desmazieres. The most frequently isolated species was $A$. flavipes (63.04\%), followed by $A$. fumigatus (16.7\%), A. terreus (13.04\%), A. carneus (5.8\%) and A. clavatus (1.44\%). The total isolates of Aspergillus from mangrove soil and leaf litters in Sarawak shown in Figure 1.

\section{Morphological Characteristics}

All the five isolates showed significant growth rate level $(\mathrm{P}<0.05)$ on the media tested as in Table 1. All the five species isolated were varying in texture, vesicle shape, pigment production and sporulation (Images 1-5).

Klich (2002) reported nearly 200 species of Aspergillus primarily from India, Europe, Egypt, Syria, tropical Africa, Japan and North America. Since there is no record for Borneo Island, this work has documented five different species of Aspergillus from the mangrove soils and leaf litters. From this preliminary observation, A. fumigatus Fresenius, A. flavipes Bainier and Sartory, A. carneus Blochwitz and A. clavatus Desmazieres, were morphologically more variable in conidial ornamentation, phialide shapes and pigmentation than described by Raper \& Fennell (1965). In this study, A. clavatus was found interesting because of its yellow pigment and long conidiophores ranging from $3-5 \mathrm{~cm}$ on the leaf litters found in Kampung Bako while the other isolate of $A$. clavatus from Sematan, had short conidiophores ranging from $2.5-3.5 \mathrm{~cm}$. Besides that, $A$. carneus showed reddish sclerotia on MEA at room temperature. This is an important character of this species. 

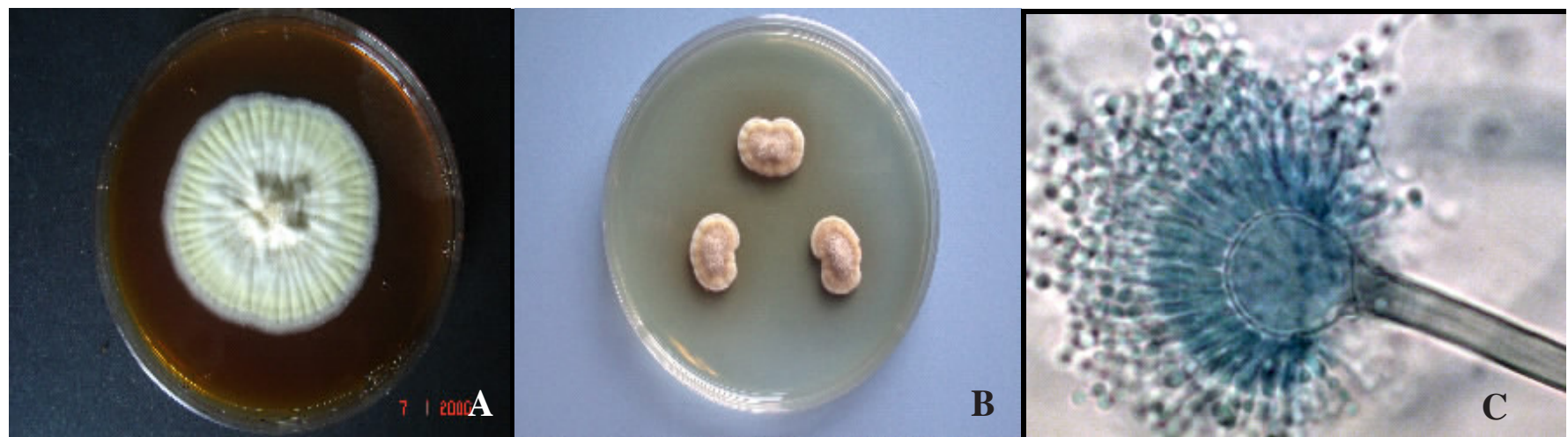

Image 1. (A-B) Colonies of $A$. flavipes on CYA and MEA at $25^{\circ} \mathrm{C}$. (C) Vesicle shape subglobose; biseriate $\mathrm{x} 40$; long phialides; spathulate to subglobose vesicles; conidia varies from globose and smooth walled
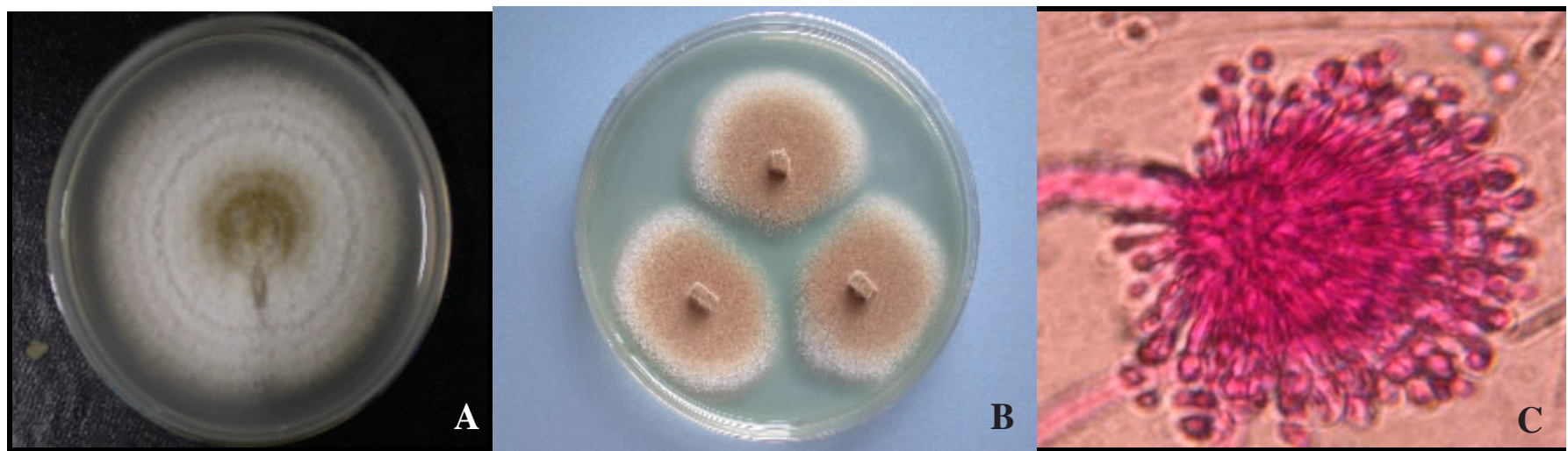

Image 2. (A-B) Aspergillus terreus on PDA and CYA at $25^{\circ} \mathrm{C}$; Colony surface- white mycelia with sandy brown spores. (C) Conidial heads- splitting into divergent column; Vesicles suglobose with biseriate sterigmata x 100 .
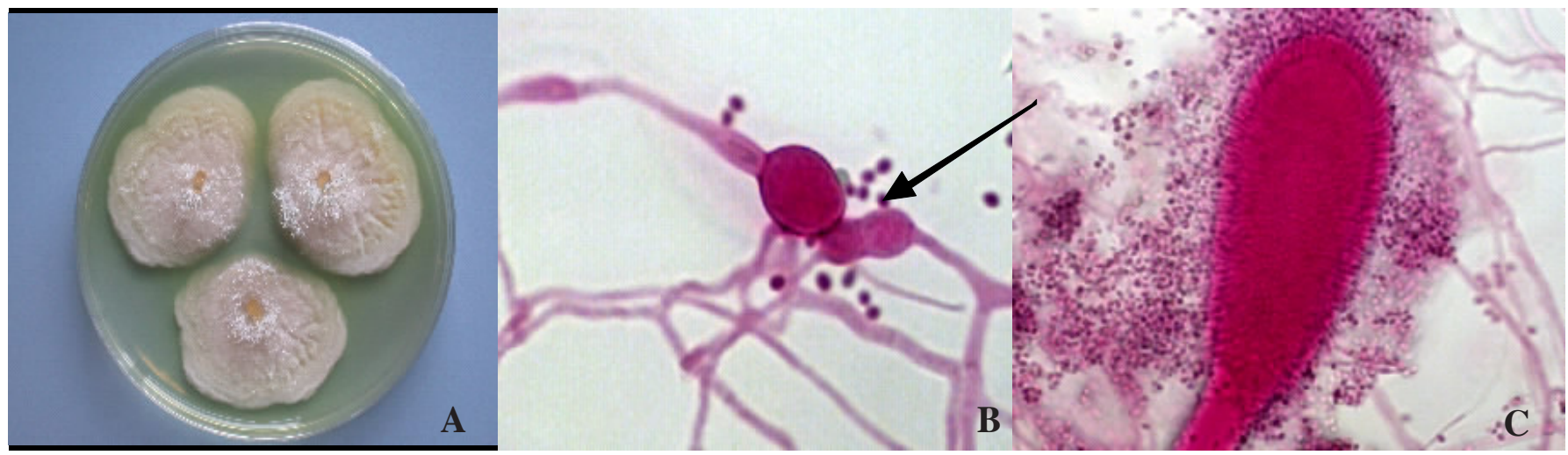

Image 3. (A) Aspergillus clavatus on MEA at $25^{\circ} \mathrm{C}$ produced yellow pigment; (c) swollen hyphal structures (b) bearing long conidiophores $(3-5 \mathrm{~cm})$; clavate shaped vesicles; conidia smooth walled, ellipsoidal x 100 .

Table 1. Average growth rate of Aspergillus species on different media

\begin{tabular}{|c|c|c|c|c|}
\hline \multirow[t]{2}{*}{ Species name } & \multicolumn{4}{|c|}{ Average growth rate (cm/day) } \\
\hline & MEA & CYA & CY20S & $\mathrm{CZ}$ \\
\hline Aspergillus flavipes & $0.55 \pm 0.03 c$ & $0.76 \pm 0.04 d$ & $0.28 \pm 0.05 a$ & $0.32 \pm 0.02 a b$ \\
\hline Aspergillus fumigatus & $0.80 \pm 1.00 \mathrm{~d}$ & $0.73 \pm 0.05 c$ & $0.53 \pm 0.03 a$ & $0.64 \pm 0.02 b$ \\
\hline Aspergillus terreus & $0.45 \pm 0.01 b$ & $0.48 \pm 0.01 a b$ & $0.37 \pm 0.01 a$ & $0.47 \pm 0.01 b$ \\
\hline Aspergillus carneus & $0.71 \pm 0.06 b$ & $0.73 \pm 0.02 b$ & $0.36 \pm 0.01 a$ & $0.75 \pm 0.02 b$ \\
\hline Aspergillus clavatus & $0.84 \pm 0.00 d$ & $0.78 \pm 0.02 c$ & $0.46 \pm 0.04 a$ & $0.55 \pm 0.03 b$ \\
\hline
\end{tabular}




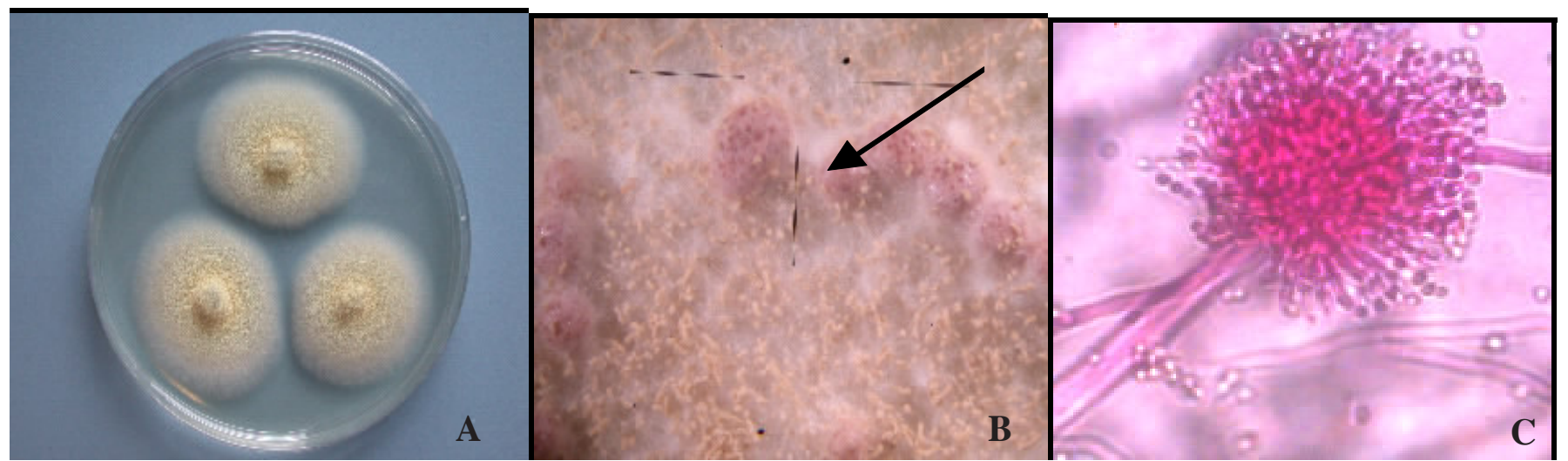

Image 4. (A) Aspergillus carneus on CYA and MEA are similar (B) reddish sclerotia on MEA only (C) subglobose vesicles; biseriate; conidia smooth walled and subglobose to globose $\times 100$.

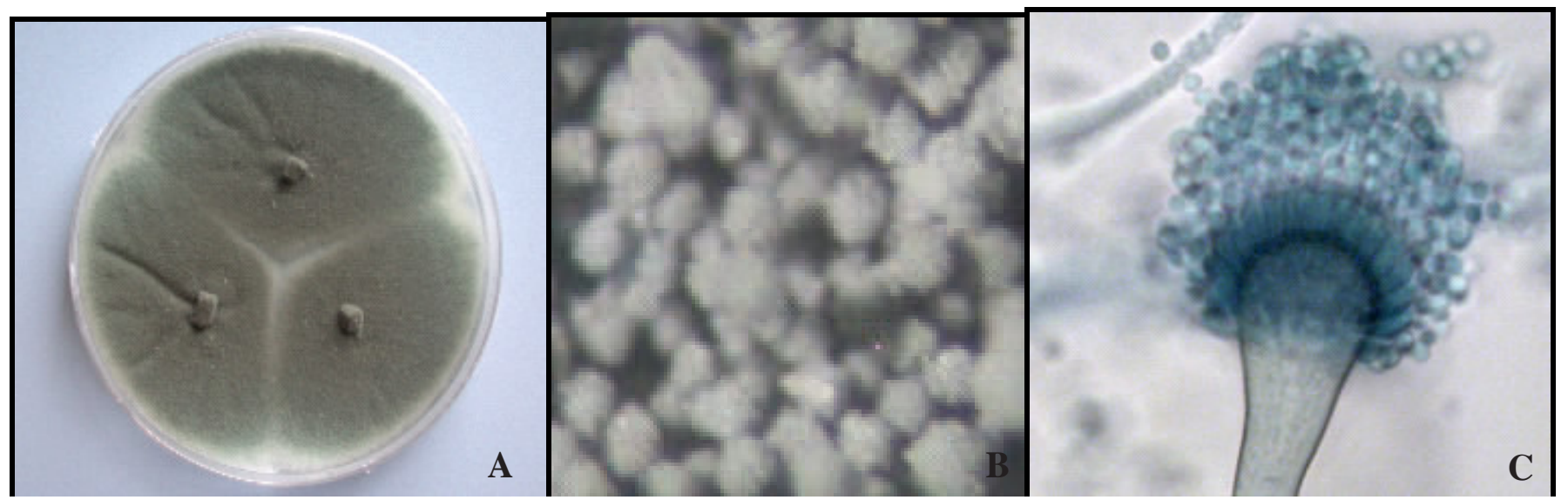

Image 5. (A) Aspergillus fumigatus on CYA at $25^{\circ} \mathrm{C}$ (B) spores white to dark greenish in color (C) radiate shaped vesicles; uniseriate; conidia smooth and subglobose in shape $\mathrm{x} 100$.

\section{Conclusion}

In conclusion, five species of Aspergillus were obtained i.e. A. fumigatus Fresenius, A. flavipes Bainier and Sartory, A carneus Blochwitz and $A$. clavatus Desmazieres are reported from mangrove soil and leaf litters at Kampung Bako, Bako, Lundu and Sematan, Sarawak. Morphological characteristics of these five species were distinct. Colony growth characteristics were media dependent and were different for each species

\section{References}

Christensen, M. \& D.E. Tuthill (1985). Aspergillus: an overview, pp. 195209. In: Samson, R.A. \& J.I. Pitt (eds.). Advances in Penicillium and Aspergillus systematics. New York: Plenum Press.

Domsch, K.H., W. Gams \& T.H. Anderson (1980). Compendium of soil fungi. Academic Press, London. New York, Torroute, Sydney San Francisco, 859pp.

Klich, M.A. (2002). Identification of Common Aspergillus species. $1^{\text {st }}$ ed. Centraalbureau voor Schimmelcultures, Utrecht, Netherlands, 116pp.

Papagianni, M. (2004). Review of fungal morphology and metabolite production in submerged mycelial process. Biotechnology advances 22: 189-259.

Raper, K.B. \& D.I. Fennell (1965). The genus Aspergillus. Williams and Wilkins, Baltimore, 686pp.

Raper, K.B. \& D.I. Fennell (1977). The genus Aspergillus. Robert Erieger Publishing Company Huntington, New York, 68pp.

Warcup, J.H. (1950). The soil plate method for isolation of fungi from soil. Nature 166: 117-118.
Distribution of Aspergillus species in mangrove soil and leaf litters

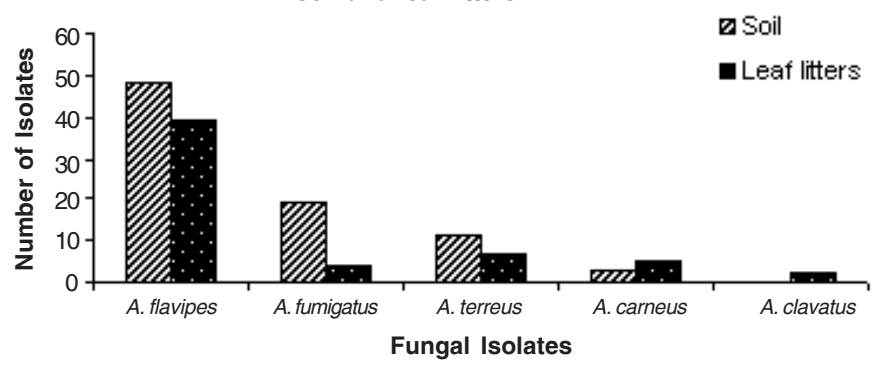

Figure 1. Total number of Aspergillus spp. isolated from mangrove soil and leaf litters 